\title{
Power Supply Management for an Electric Vehicle Using Fuzzy Logic
}

\author{
Yolanda Pérez-Pimentel, ${ }^{1}$ Ismael Osuna-Galán (iD), \\ Carlos Avilés-Cruz, ${ }^{2}$ and Juan Villegas-Cortez ${ }^{2}$ \\ ${ }^{1}$ Polytechnic University of Chiapas, Carretera Tuxtla Gutierrez, Portillo Zaragoza Km 21+500, Suchiapa, Chiapas, Mexico \\ ${ }^{2}$ Autonomous Metropolitan University-Azcapotzalco, Av. San Pablo Xalpa 180, Reynosa Tamaulipas, \\ Mexico City 02200, CDMX, Mexico \\ Correspondence should be addressed to Ismael Osuna-Galán; iosuna@upchiapas.edu.mx
}

Received 30 May 2018; Accepted 17 October 2018; Published 5 November 2018

Academic Editor: Christian W. Dawson

Copyright (c) 2018 Yolanda Pérez-Pimentel et al. This is an open access article distributed under the Creative Commons Attribution License, which permits unrestricted use, distribution, and reproduction in any medium, provided the original work is properly cited.

The technology of power electronic systems has diversified into industrial, commercial, and residential areas. Developing a strategy to improve the performance of the electrical energy of an electric vehicle (EV) requires an analysis of the model that describes it. EVs are complex mechatronic systems described by nonlinear models and, therefore, its study is not an easy task. It can improve the performance of a battery bank by creating new batteries that allow for greater storage or by developing a management energy system. This article shows the development of a power supply management system based on fuzzy logic for an electric vehicle, in order to minimize the total energy consumption and optimize the battery bank. The experimental result is shown using the fuzzy controller under standard operating conditions. An increase in battery performance and overall performance of energy consumption is shown. Speed signals acquired show improvements in some dynamic, such as overshoot, settling time, and steady-state error parameters. It is shown that this fuzzy controller increases the overall energy efficiency of the vehicle.

\section{Introduction}

Some of the reasons why cars that use alternative sources of energy have become a necessity are emissions regulations, advances in electric motor technology, and the creation of high-performance batteries [1]. Several companies around the world have begun to consider more seriously the commercialization of electric vehicles (EV). The technology of electric vehicles has achieved a performance comparable to combustion engines. Hybrid cars combine properties to improve EV performance, electric traction engines provide fast acceleration, and the internal combustion engine works well at constant speeds. $([2,3])$.

Currently, most EVs are powered from an external generating plant, which feeds a battery bank. Energy storage methods include chemical energy stored in the vehicle by batteries. The low power density and a reduced life cycle are some of the shortcomings of the electrochemical battery.
A great advance is the creation of new energy storage systems composed of solar cells, high-performance batteries, or electronic power systems. The use of power electronics technology using power consumption control of the battery bank reduces the discharge cycle of the battery and increases the EV travel distance [4].

Figure 1 shows the EV UPChis 01 created by professors and students of mechatronic engineering of Polytechnic University of Chiapas. This article proposes an approach to power management applications in EV based on reducing the current power supplied by the battery bank. The main advantage of this proposal to improve the life cycle of the battery bank and improve performance using a fuzzy system. The rest of the paper is organized as follows. First, the characteristics of the electric vehicle and the model used in this study are shown. It describes the input and output variables, membership functions, and fuzzy system rules. It showed experimental results of the proposed solution, comparing the EV 


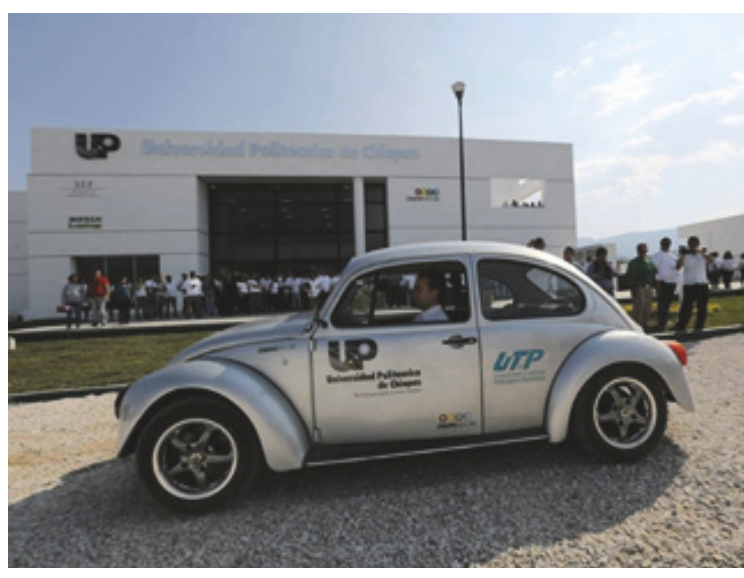

FIGURE 1: Electric vehicle UPChis01.

performance under normal conditions. Finally, the discussion of the results will be made in the last section.

\section{Related Works}

In Mexico, several universities have developed electric vehicles that meet various international quality standards; the Faculty of Engineering of the UNAM recently built the car "Kalani", which is a three-wheeler vehicle with a steel frame and fiberglass. It has a weight of 50 kilos and is 120 centimeters wide by 220 centimeters long and 80 centimeters high and also features lithium cells 1000 watts and an efficiency of 14 kilometers on a single charge. Moreover, the School of Mechanical and Electrical Engineering of the National Polytechnic Institute of México modified a Volkswagen sedan car to build an electric car; it works in a voltage range of 36-92 volts. The battery bank consists of six deep-cycle $8 \mathrm{~V}$ leadacid batteries each. The Center for Automotive Mechatronics Research of the Monterrey Institute of Technology and Higher Education Institute of Technology, campus Toluca, is currently developing a commercial EV. Companies to distribute their products within cities will use this EV; this project is in coordination with the Energy Agency of Mexico.

It is necessary to optimize the full use of the available energy of an EV battery subjected to different speeds. Most schemes use a PID controller to manage battery power. The conventional PID controller requires some adjustment for a quick and dynamically acceptable response. Perform a PID control; a precise adjustment is required to obtain a fast response that adapts dynamically to the model; the circuits of the operational amplifiers are used to measure the parameters of a linear model. The main disadvantage of circuits is their degradation due to time and high temperatures.

Several articles ([5-9]) present controllers based on fuzzy logic systems to monitor the power consumption, power output, or pulse width modulation (PWM) used in an EV.

The self-excited induction generator used in these motors has the inherent problem of fluctuations in the size and frequency of voltage changes in speed. The solution to this problem is to rectify the variable frequency voltage at the generator terminals and use a PWM inverter to receive and send the electric power. The goal is to track and extract the maximum power of the power system and transfer this power to the local isolated load.

\section{Materials and Methods}

3.1. EV Components. The general characteristics and the components of the electric vehicle are described. It is a Volkswagen sedan car with a 4-cylinder internal combustion engine, model 2000 , with a mass of $550 \mathrm{~kg}$. The electric motors used are Chinese manufacture and detailed datasheets were not available. There is a simple description of the engine conditions.

The basic description of the components of EV UPChis01 is described in Table 1.

There are different types of architecture for electric vehicles [6]. Some possibilities are 1 to 4 electrical machines, AC or DC electric machines, with or without a gearbox, high or low voltage batteries, and one or three charging phases. The chosen architecture is shown in Figure 2.

The original design had some problems that affected the performance of the engine and batteries. The batteries are composed of a liquid electrolyte of sulfuric acid and lead plates forming the anode and the cathode. This type of battery was the most common for traction of electric vehicles, given its robustness, great offer in the market, and low price. However, they require periodic revision and replacement of the electrolyte level, which evaporates during recharging. In addition, they have a significant environmental impact if they are not recycled and have a short life cycle.

The efficiency of the batteries is directly affected by the acceleration of the car. On many occasions, the charge of the battery bank was unbalanced. It was estimated that the battery bank should be changed every 2 years and cost is around US\$3,000. In Mexico, this cost is very high. So it was necessary to perform an energy manager for the EV.

The manufacturers claim that the electric motor reaches speeds above $100 \mathrm{~km} / \mathrm{h}$; it was not safe for the user to reach that speed due to the type of batteries used. The electric motor may suffer wear of the bushings, so it should be checked periodically. An adequate way to perform this review is by analyzing the noise and heat levels generated by the engine. If the motor begins to present increases in temperature or noise higher than its normal condition then there is a bushing wear. The engine data sheet does not contain information on these parameters. The operating limits had to be established according to the experience of use of the vehicle. In the average in which the internal part of the engine is inspected in a timely manner and the worn parts are replaced, maintenance cost overruns will be avoided and a better performance of the vehicle will be obtained, as well as a longer service life of the vehicle.

It is clear that these batteries are inadequate for the development of EV. They have a low energy density and low efficiency is usually $70-75 \%$. However, this type of batteries was used because they are popular in Mexico.

It was decided to make changes in the electric car to increase user safety. Table 2 shows the components of the modified version of the $\mathrm{EV}$. 
TABLE 1: Description of the original EV components.

\begin{tabular}{lc}
\hline Quantity & Description \\
\hline 1 & Brushless PMM motor 10 KW Continuous, 24 KW Peak (at 72 volts), 6000 RPM \\
1 & Motor Controller ALLTRAX mod. SR-72400 Series, 12-72V, 400 A \\
12 & Batteries 6 VCD \\
1 & 5-speed manual transmission. and 1 reverse \\
4 & Rin wheels 16 \\
\hline
\end{tabular}

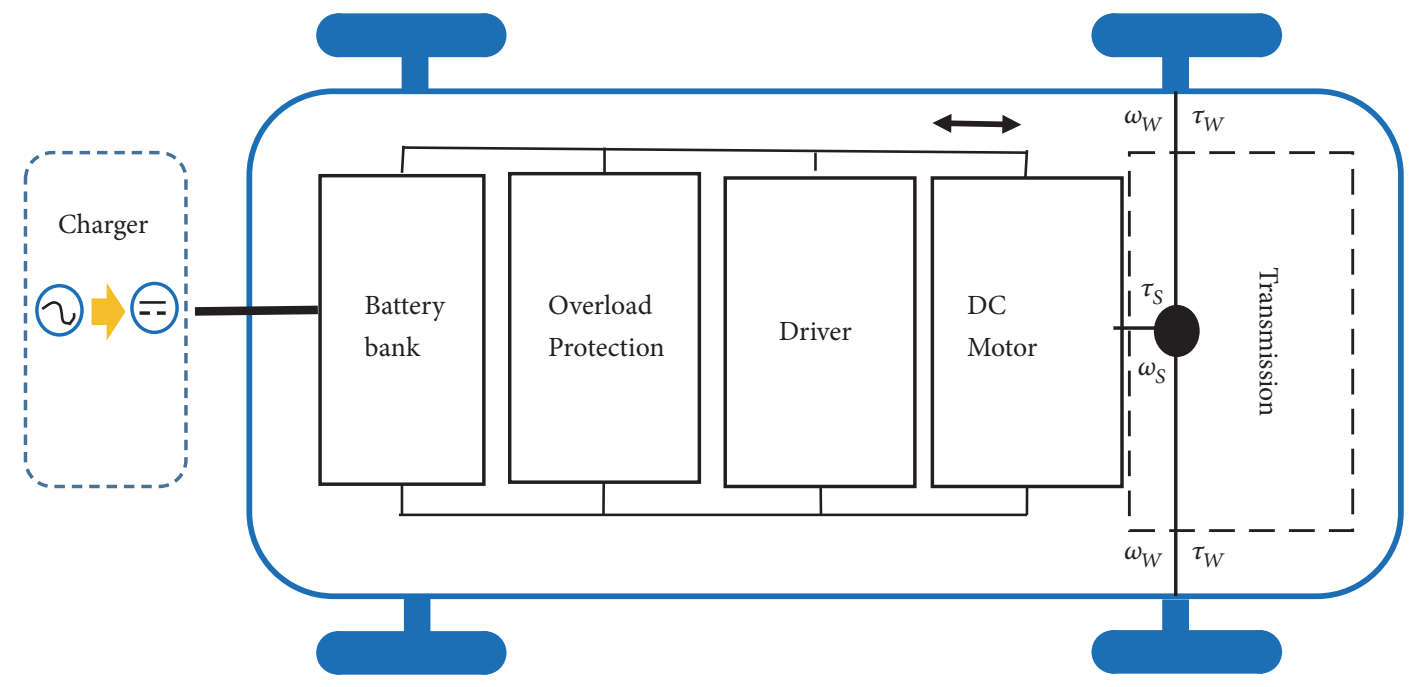

FIGURE 2: Main components of the EV.

LabVIEW software is used to implement this integrated system in a CompactRIO from the National Instruments Company. A CompactRIO is a real-time embedded industrial controller made for industrial control systems. The CompactRIO is a combination of a real-time controller, reconfigurable input/output modules, FPGA module, and an ethernet expansion chassis. LabVIEW and National Instruments technology are used in many engineering applications [10].

3.2. Mathematical Analysis. The forces exerted on the electric vehicle are due to gravity, wind, rolling resistance, and inertial effect being analyzed. Such forces can be observed in Figure 3. In $[9,11]$ there is a detailed analysis of these forces.

The tire force of a vehicle may be described by the following equations:

$$
\begin{aligned}
& F_{\text {traction }} \\
& =\underbrace{M_{E V} \dot{v}_{E V}}_{F \text { inercial }}+\underbrace{M_{E V} g}_{W} \sin (\alpha) \\
& +\operatorname{sign}\left(v_{E V}\right) \underbrace{\overbrace{M_{E V} g \cos (\alpha)}^{\text {Fnormal }}}_{\text {Ffriction }} c_{r r} \\
& +\operatorname{sign}\left(v_{E V}+v_{\text {wind }}\right) \underbrace{\frac{1}{2} \rho_{\text {air }} C_{d r a g} A\left(v_{E V}+v_{\text {wind }}\right)^{2}}_{\text {Fwind }} \\
& C_{\text {drag }}=0.01\left(1+\frac{3.6}{100} v_{E V}\right)
\end{aligned}
$$

The description of each of the variables in the model is shown in Table 3.

3.3. Electric Batteries. These are general battery voltage ranges 6-cell lead-acid:

(1) Open circuit (inactive) load: $12.6 \mathrm{~V} 12.8 \mathrm{~V} \sim(2.10 \sim$ $2.13 \mathrm{~V}$ per cell)

(2) Open circuit at full discharge: $11.8 \mathrm{~V} \sim 12.0 \mathrm{~V}$

(3) Loaded full download $10.5 \mathrm{~V}$

(4) Continuous charge preservation (float) $13.4 \mathrm{~V}$ for gel electrolyte; $13.5 \mathrm{~V}$ for AGM (Absorbed Glass Mat), and $13.8 \mathrm{~V}$ for cells common fluid electrolyte

(5) All voltages are referenced at 20 and must conform $0.022 \mathrm{~V} /{ }^{\circ} \mathrm{C}$ by temperature changes

(6) Recommendations on the float voltage vary according to the manufacturer's recommendations

(7) A float voltage accurate $( \pm 0.05 \mathrm{~V})$ is critical on longevity; very low (sulfation) is almost as bad as high (corrosion and loss of electrolyte)

(8) Typical load (daily): $14.2 \mathrm{~V}$ to $14.5 \mathrm{~V}$ (depending on the manufacturer's recommendations)

(9) Equalization charge (battery electrolyte fluid): $15 \mathrm{~V}$ for no more than 2 hours. The battery temperature must be controlled 
TABLE 2: Description of the modified EV components.

\begin{tabular}{lc}
\hline Quantity & Description \\
\hline 1 & Brushless PMM motor 72V 12 kW 6500 rpm \\
1 & Motor Controller ALLTRAX mod. SR-72400 Series, 12-72V, 400 A \\
1 & CompactRIO 9074 National Instruments \\
1 & CompactRIO module NI 9207 analogic input National Instruments \\
1 & CompactRIO module NI 9262 analogic output National Instruments \\
1 & CompactRIO module NI 9583 Controller Area Network, Bus Interfaces \\
12 & Batteries 6 VCD \\
1 & 5-speed manual transmission. and 1 reverse \\
4 & Rin wheels 16 \\
\hline
\end{tabular}

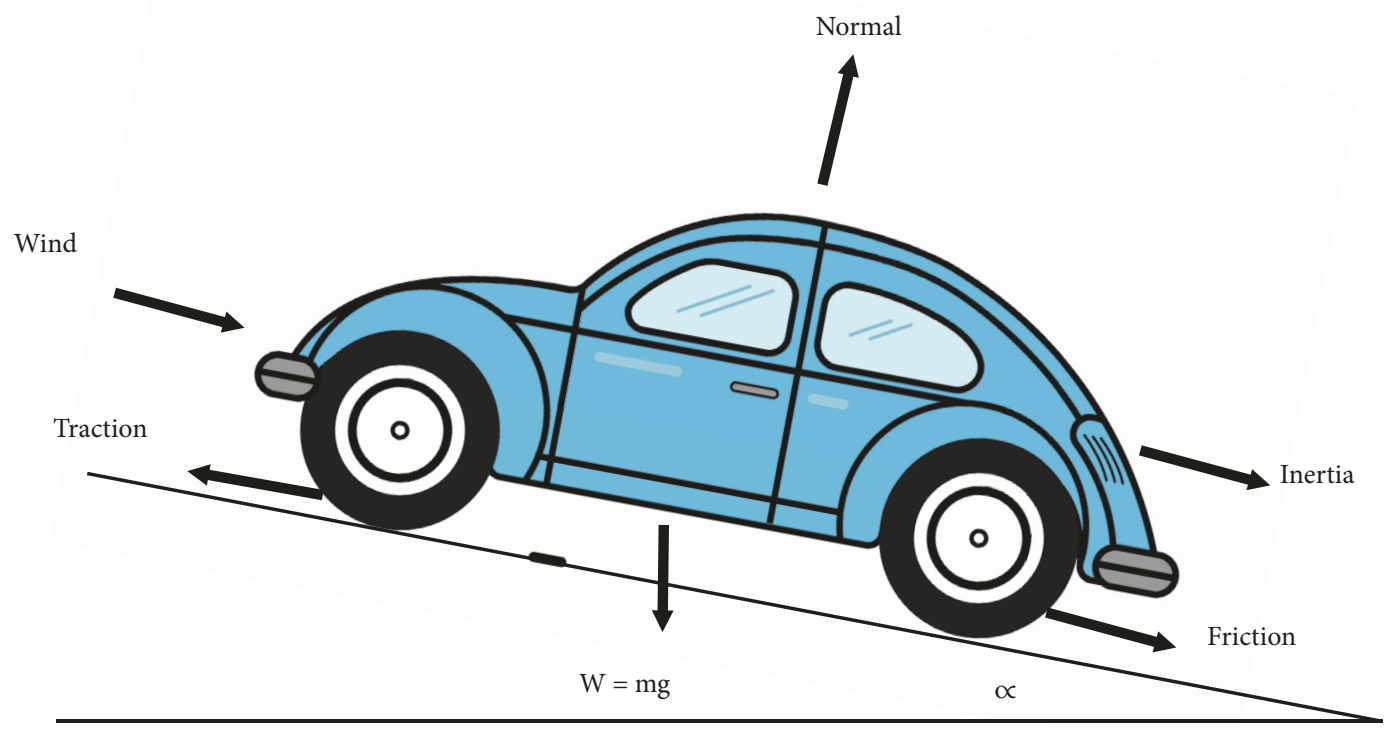

FIGURE 3: Force analysis.

TABLE 3: Description of model parameters EV.

\begin{tabular}{lcc}
\hline PARAMETER & DESCRIPTION & UNITS \\
\hline$F_{\text {traccion }}$ & Tractive force & $\mathrm{N}$ \\
$F_{\text {inertial }}$ & Inertial forcé & $\mathrm{N}$ \\
$F_{\text {friccion }}$ & Frictional force & $\mathrm{N}$ \\
$W$ & Weight EV & $\mathrm{N}$ \\
$F_{\text {normal }}$ & Normal strength & $\mathrm{N}$ \\
$F_{\text {wind }}$ & Resistance force due to wind & $\mathrm{N}$ \\
$\alpha$ & Angle surface & radians \\
$M_{E V}$ & Mass EV & $\mathrm{kg}$ \\
$v_{E V}$ & Speed EV & $\mathrm{m} / \mathrm{s}$ \\
$\dot{v}_{E V}$ & EV acceleration & $\mathrm{m} / \mathrm{s}^{2}$ \\
$\rho_{\text {air }}$ & Density of air at 30 C 1,650 & $\mathrm{~kg} / \mathrm{m}^{3}$ \\
$A$ & frontal área & $\mathrm{m}^{2}$ \\
$c_{r r}$ & Tire rolling resistance & \\
$C_{\text {drag }}$ & Aerodynamic drag coefficient & $\mathrm{m} / \mathrm{s}$ \\
$v_{\text {wind }}$ & Wind speed &
\end{tabular}


TABLE 4: Description of the fuzzy system.

\begin{tabular}{|c|c|c|}
\hline Linguistic variable & Grammar & Membership function \\
\hline \multirow{7}{*}{ SLOPE } & Descending & Trapezoidal \\
\hline & Medium Descending & Triangle \\
\hline & Flat Descending & Triangle \\
\hline & Flat & Triangle \\
\hline & Flat Ascending & Triangle \\
\hline & Medium Ascending & Triangle \\
\hline & Ascending & Trapezoidal \\
\hline \multirow{4}{*}{ DEEP OF DISCHARGE } & Full & Trapezoidal \\
\hline & High & Triangle \\
\hline & Normal & Trapezoidal \\
\hline & Eco Mode & Trapezoidal \\
\hline \multirow{6}{*}{ SPEED } & Slow & Trapezoidal \\
\hline & Low & Triangle \\
\hline & Normal low & Triangle \\
\hline & Normal & Triangle \\
\hline & Normal High & Triangle \\
\hline & High & Trapezoidal \\
\hline \multirow{6}{*}{ CORRECTED SPEED } & Slow & Trapezoidal \\
\hline & Low & Triangle \\
\hline & Normal low & Triangle \\
\hline & Normal & Triangle \\
\hline & Normal High & Triangle \\
\hline & High & Trapezoidal \\
\hline
\end{tabular}

(10) After full load terminal voltage drops quickly to $13.2 \mathrm{~V}$ and then slowly to $12.6 \mathrm{~V}$

3.4. Fuzzy Sets. The main objective of this work was to apply a fuzzy logic controller to verify if the controller improves the power consumption of the EV. Following these ideas, the fuzzy inference system developed is based on rules "if... then...".

In this section, the development of the fuzzy system will be described. In [8] an experimental test was created for electricity consumed in an EV.

There are several heuristic approaches applied to electric or hybrid vehicles. Using the results of articles 2 and 3, a fuzzy system was built to act as an EV power manager.

In this case, the fuzzy system is a power division manager and controls all systems built into the vehicle. Through a network of CAN controller (Controller Area Network), that is, a communication protocol based on a bus topology for the transmission of messages in a distributed environment, the network is used to communicate all devices each other.

Some of the reasons why triangular and trapezoidal functions are used are explained in [12]. Wu makes a comparison between the different membership functions by identifying the best situations for each use. Three reasons are highlighted below:

(1) Construction: it refers to methods to obtain membership functions. Generally, there are two methods to create a membership function: a mathematical model is needed to describe the plant and use optimization techniques to adjust the parameters. It is easier to model variables if a linearization is performed such as to control the current of the battery required by the power controller.

(2) Monotonicity: it describe to the system and conservation the original structure during a process. A monotonic function is expressed as a mathematical expression that does not change the given order. A trapezoidal function works better than Gaussian function.

(3) Computational cost: it is the control actions in real time depending on the algorithm used. An algorithm that minimizes the number and order of operations is necessary. A controller that performs a faster process is the desired one. For a Mamdani type system with 50 rules or less, the Gaussian function works better. However, in the case of this study, more than 100 rules are used and an inference with trapezoids and triangles functions is made faster.

Table 4 indicates the linguistic variables, their membership functions, and the type of function used in each case. Figures 4-7 show the variables of the slope, speed, depth of discharge, and speed corrected, respectively. The systems is a MISO controller type (multiple input single output) which has inputs, road slope, depth of discharge, and driving speed, and output, corrected speed. 


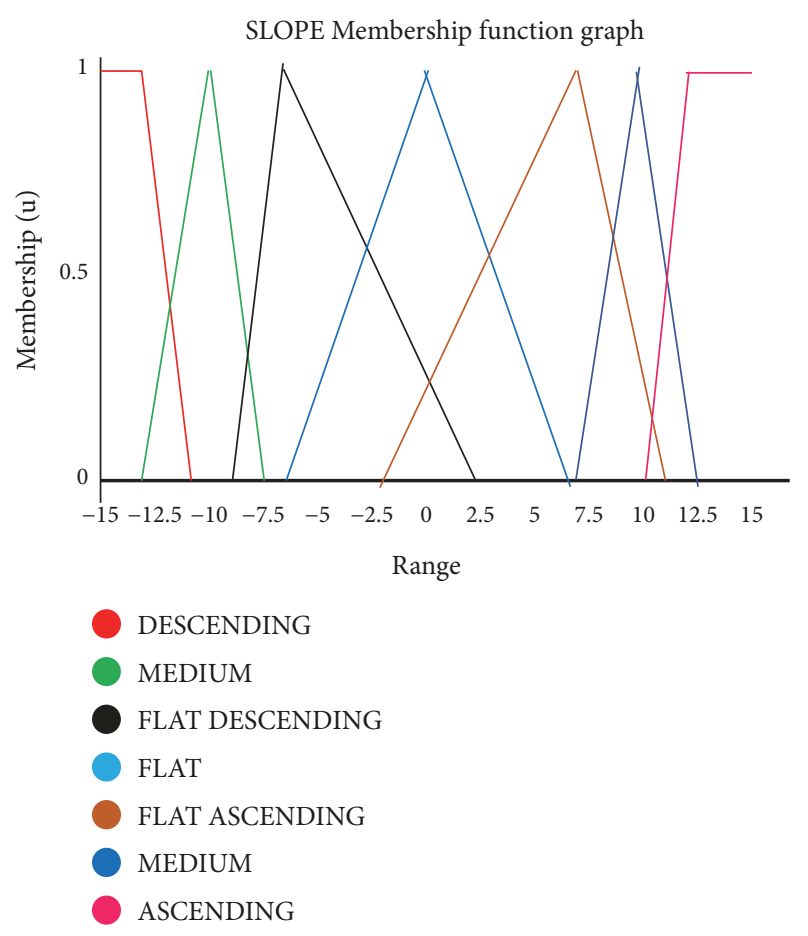

FIGURE 4: Input variable SLOPE.

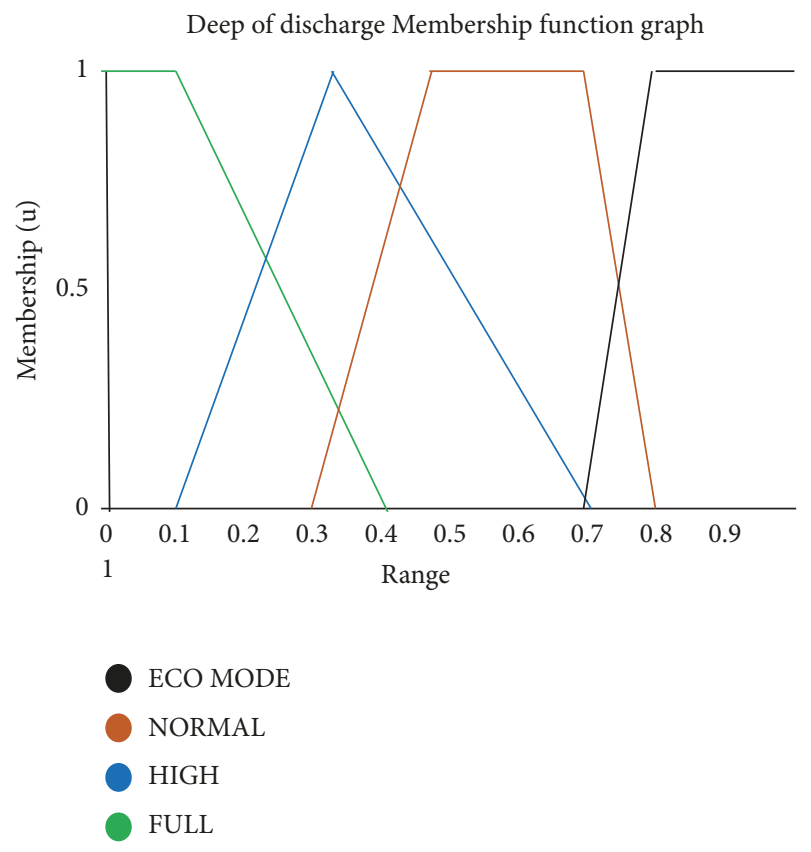

FIgURE 5: Input variable DEEP OF DISCHARGE.

3.5. Fuzzy Rules. Driver tasks slow EV to reduce energy consumption of the vehicle. First, the slope of the inputs is derived from the gradient of the road, depth of discharge is calculated from the EV modeling, and speed is used. The fuzzy controller acts in situations where the depth of discharge is greater than $70 \%$ and applied directly on vehicle performance and the system slows to protect the battery

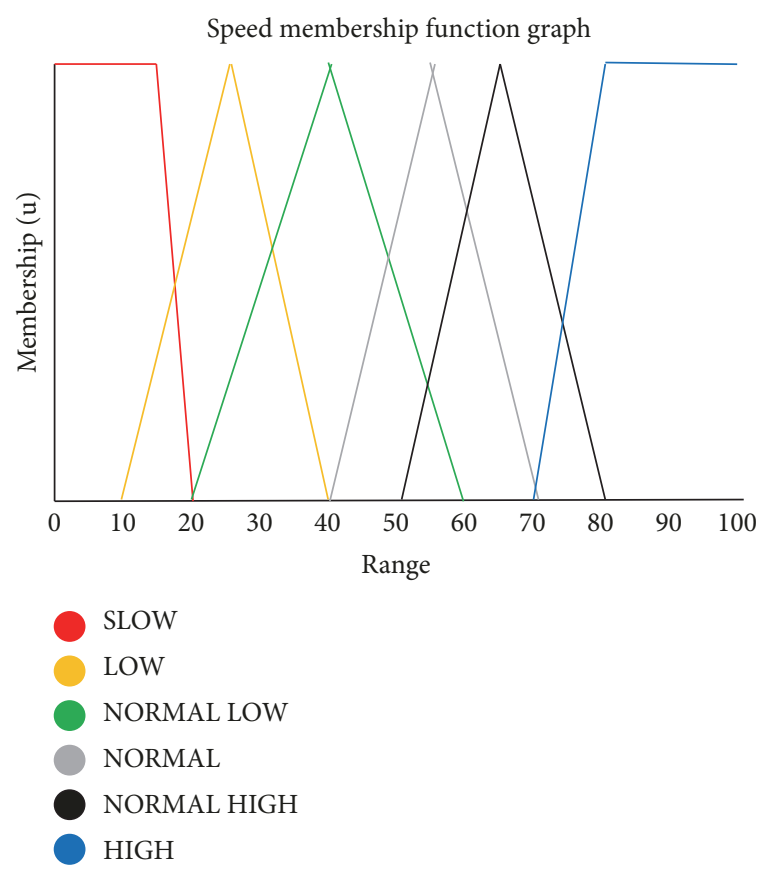

FIgURE 6: Input variable SPEED.

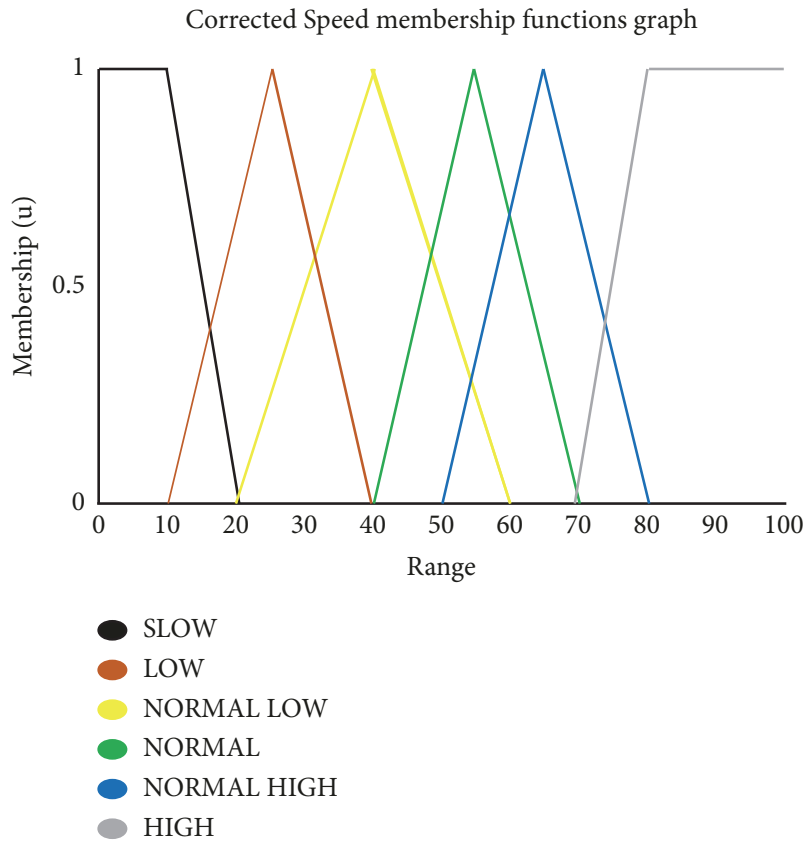

FIgURE 7: Output variable CORRECTED SPEED.

power by reducing the power consumption, since it is directly proportional to the tensile force of the EV. This driver works in different environments (flat slope of the road, ascending and descending scenarios).

There are 140 rules. Figure 8 shows the fuzzy system developed in the Fuzzy System Designer of LabVIEW. For example, one of these rules is as follows: 


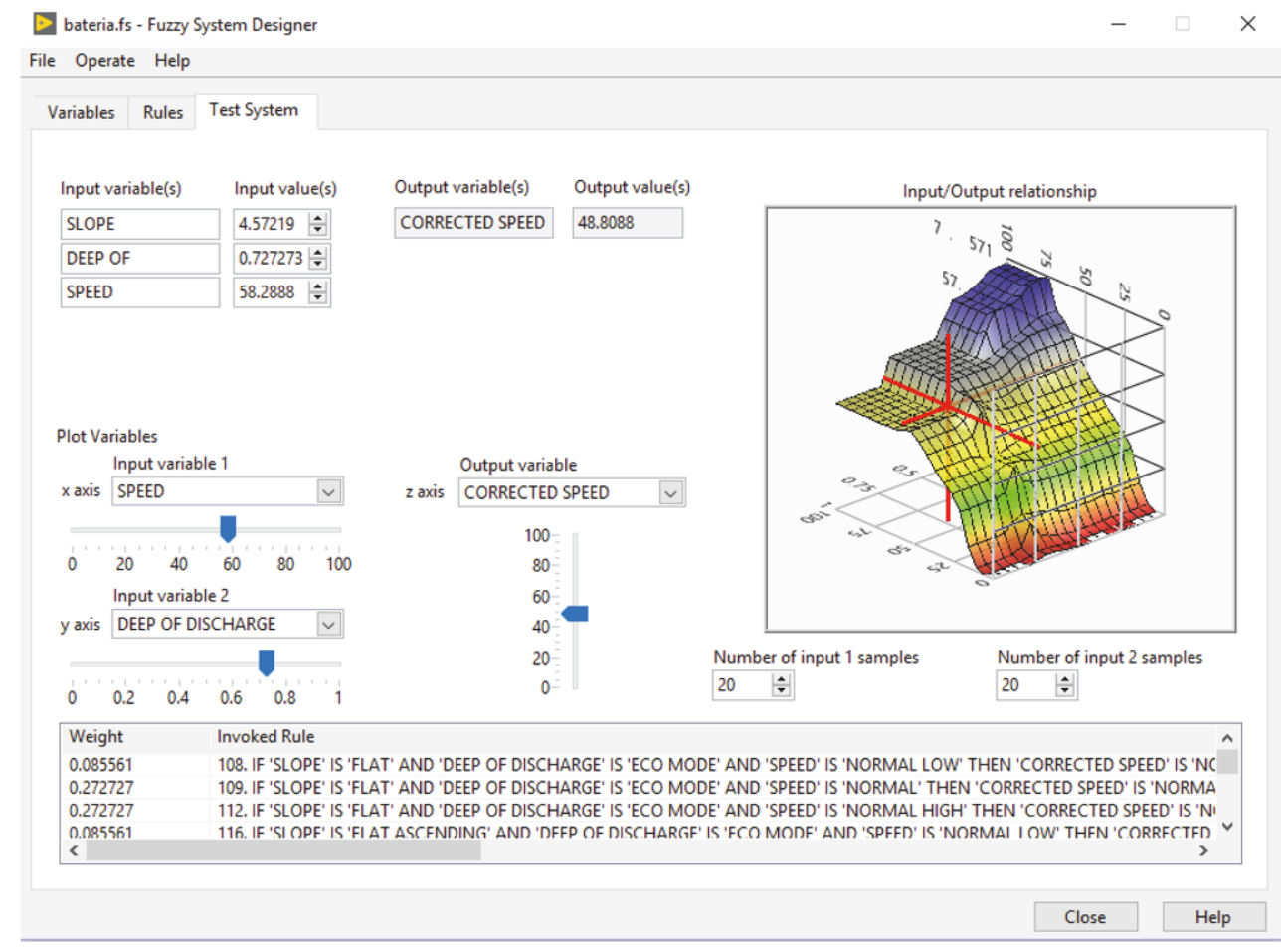

Figure 8: LabVIEW fuzzy system designer.

"If SLOPE = FLAT, and DEEP OF DISCHARGE = ECO MODE and SPEED $=\mathrm{HIGH}$ and then a SPEED CORRECTED = NORMAL".

In this case, the fuzzy controller acts in the following manner: the speed is reduced (output variable CORRECTED SPEED) since a discharge of the batteries superior to $70 \%$ was detected (ECO MODE set) so that the speed requested by the user is modified by a value of speed adapted to the conditions of the battery and road conditions (FLAT set).

\section{Results and Discussion}

In 2015, the design and construction of EV UPChis01 were carried out with financing from the Ministry of Education of Mexico. In 2016, a grant was awarded to improve the EV design. This research began in 2017. The proposal was presented to improve battery performance and improve efficiency using intelligent control.

A driving cycle consists of microtravel and has a period of 5 to 40 minutes. This duration must contain sufficient microtrips that reflect driving behavior in the real world. The following are some basic cycle parameters carried out by a section of the new highway Tuxtla Gutierrez, Suchiapa, Villaflores (Duration: $499 \mathrm{~s}$; distance: $5.4 \mathrm{~km}$; average speed: $60.2 \mathrm{~km}$ / h; maximum speed: $85.5 \mathrm{~km} / \mathrm{h}$ ). Figure 9 shows the minitrip used in experimental results.

In any case, it is important to get key variables such as speed, acceleration, distance, and slope of the route. When talking about the development of the management cycle, three steps are important: route selection, data collection, and

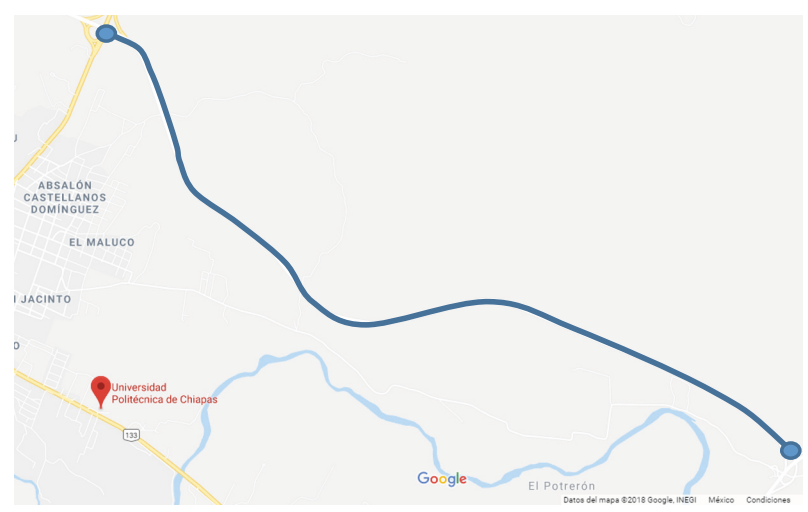

FIGURE 9: Minitrip route.

construction cycle. Route selection involves selecting the course to describe the cycle. It is to determine whether the route is a highway with a constant velocity, arterial roads, or urban driving, for example. Data collection is the ability to collect data parameters with appropriate sensors to describe the driving cycle. Finally, several microtrips are made and once all the data is collected, the time domain function of the vehicle speed is constructed.

Speed driving cycle and controlled speed are expressed in Figure 10. In the chart, the white line represents the speed of a travel cycle without using the fuzzy controller. The red line represents the speed of a trip cycle using the fuzzy controller. If the fuzzy system is deactivated then a higher average speed is observed. 
TABLE 5: Average values of energy consumption during a cycle trip.

\begin{tabular}{lll}
\hline Parameter & EV result & Improvement \\
\hline Energy consumption without controller & $5.62 \mathrm{~W} \mathrm{~h}$ \\
Energy consumption with fuzzy control & $3.95 \mathrm{~W} \mathrm{~h}$ & $29.62 \%$ \\
\hline
\end{tabular}

TABLE 6: Average values of power loss during a cycle trip.

\begin{tabular}{lcc}
\hline Parameter & EV result & Improvement \\
\hline Power losses without controller & $1479 \mathrm{~W}$ & \\
Power losses with fuzzy control & $1135 \mathrm{~W}$ & $23.25 \%$ \\
\hline
\end{tabular}

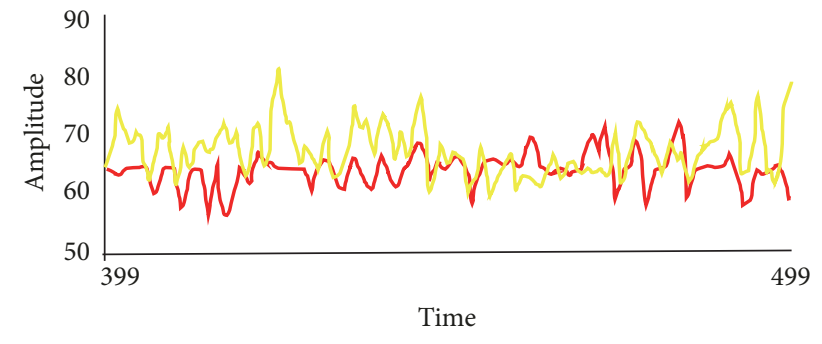

- Speed without controller

- Corrected Speed

FIGURE 10: EV speeds for a minitrip.

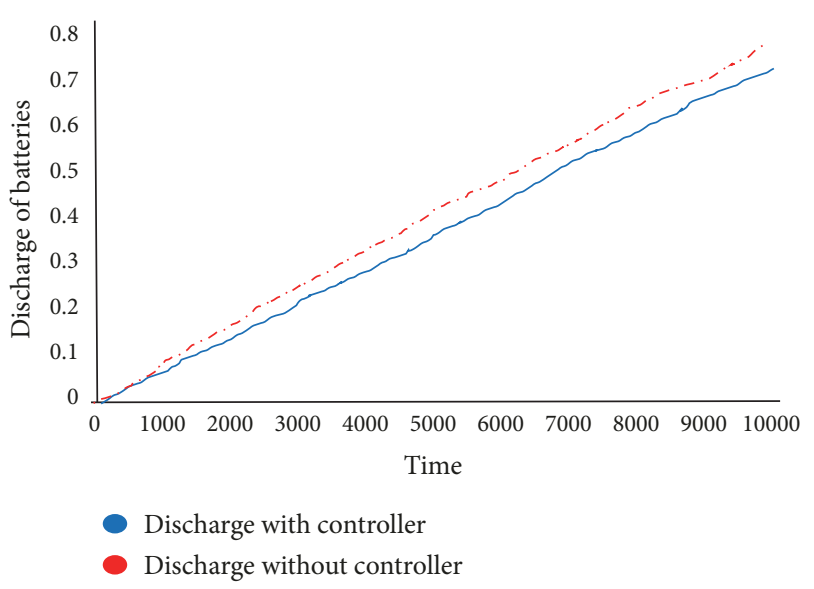

FIGURE 11: Discharge time of the EV battery bank.

In Tables 5, 6, and 7, the average values of energy consumption, power loss, and current of a travel cycle are shown. The mean values obtained in the experimental results show a general improvement of $25.7 \%$ with the application of the fuzzy system. These results give a sign of improvement in the performance of the battery bank.

In Figure 11, the depth of discharge versus time is illustrated. Increased autonomy of the vehicle is visible when the cycle with the controller has a time interval longer battery to drain all time.

The data is saved and analyzed when an empty battery discharge value is reached. This value is close to $95 \%$. Energy, current, and power loss were analyzed under normal conditions of use and will be purchased with the results obtained with the fuzzy controller. A difference in the discharge level of the batteries is observed in a travel cycle of 10,000 seconds under normal road conditions. It is possible to take a longer route when the fuzzy system acts on the EV (white line).

\section{Conclusions}

Experimental tests show that with the integrated controller in the EV desired results were obtained. In all, lower values for all parameters analyzed were generated values, demonstrating the effectiveness of the system implementation. The electric power consumption was reduced in all tests, giving integrity and security to the battery bank.

The results obtained in the different tests, in which the components of the electric vehicle were demanded to the maximum, were able to determine its functionality. This allowed us to carry out the programming of the diffuse system in order to make the most of its efficiency. The results of the tests show that the electric motor does not overheat at any time. The temperature increases gradually to levels below $92^{\circ} \mathrm{C}$.

A longer trip is a success of the system since it prevents the battery discharged. This offers the driver the opportunity to find a nearby charging station. It will be necessary to determine whether the conduct for the highway has the same behavior as the system in an urban environment. It is likely that the speed is reduced naturally by traffic conditions and speed limits that occur in a city.

Presumably, in most scenarios highway speeds higher than the EV can be a viable solution for communication between small towns near the city. Therefore, to improve system analysis and conducting research on different topics are adopted in the project.

Suggestions for future studies are in the sense of improving the model of the electric motor using a battery model LiIon or applying new types of controllers such as Fuzzy PID or fuzzy neural networks.

It has a list of mechanical and electrical elements and the restrictions that are required to make the conversion of the internal combustion vehicle into an EV possible.

\section{Data Availability}

The software used to support the findings of this study has not been made available because it was developed for 
TABLE 7: Current average values over a cycle trip.

\begin{tabular}{lcr}
\hline Parameter & EV result & Improvement \\
\hline Battery bank current without controller & $34.95 \mathrm{~A}$ \\
Battery bank current with Fuzzy control & $26.44 \mathrm{~A}$ & $24.34 \%$ \\
\hline
\end{tabular}

a CompactRIO 9074 with specialized modules; it does not work on a computer; however, it is possible to share the *.fs file used. LabVIEW Fuzzy System Designer is required. Information about the electric vehicle can be revised in the following links: https://www.youtube.com/watch?v=3zBBKnpkKT4 http://www.transporte.mx/politecnico-de-chiapasdesarrolla-auto-electrico/ https://www.reforma.com/aplicacioneslibre/articulo/default.aspx?id=469585\&md5=ca4ea412a924d795f6234dcc7a3a5611\&ta $=0 d f d b a c 11765226904 c 16 c b 9 a-$ dlb2efe https://mobile.diario.mx/Economia/2015-02-23_f49aea7b/crean-estudiantes-vehiculo-electrico-en-chiapas/

\section{Conflicts of Interest}

The authors declare that there are no conflicts of interest regarding the publication of this paper.

\section{Acknowledgments}

The authors want to thank the financial support received through the Research Grant PROMEP.

\section{References}

[1] T. Muneer, A. Doyle, and M. L. Kolhe, Electric Vehicles: Prospects and Challenges, Elsevier, 2017.

[2] D. A. Howey, R. F. Martinez-Botas, B. Cussons, and L. Lytton, "Comparative measurements of the energy consumption of 51 electric, hybrid and internal combustion engine vehicles," Transportation Research Part D: Transport and Environment, vol. 16, no. 6, pp. 459-464, 2011.

[3] J. Larminie and J. Lowry, Electric Vehicle Technology Explained, John Wiley \& Sons, 2012.

[4] R. Maia, M. Silva, R. Araujo, and U. Nunes, "Electric vehicle simulator for energy consumption studies in electric mobility systems," in Proceedings of the 2011 IEEE Forum on Integrated and Sustainable Transportation Systems, FISTS 2011, pp. 227232, Austria, July 2011.

[5] M. Kandi-D, M. Soleymani, and A. A. Ghadimi, "Designing an optimal fuzzy controller for a fuel cell vehicle considering driving patterns," Scientia Iranica, vol. 23, no. 1, pp. 218-227, 2016.

[6] H. Hemi, J. Ghouili, and A. Cheriti, "A real time fuzzy logic power management strategy for a fuel cell vehicle," Energy Conversion and Management, vol. 80, pp. 63-70, 2014.

[7] A. O. Al-Jazaeri, L. Samaranayake, S. Longo, and D. J. Auger, "Fuzzy Logic Control for energy saving in Autonomous Electric Vehicles," in Proceedings of the 2014 IEEE International Electric Vehicle Conference, IEVC 2014, Italy, December 2014.

[8] A. A. Ferreira, J. A. Pomilio, G. Spiazzi, and L. de Araujo Silva, "Energy management fuzzy logic supervisory for electric vehicle power supplies system," IEEE Transactions on Power Electronics, vol. 23, no. 1, pp. 107-115, 2008.
[9] L. Pugi, F. Grasso, M. Pratesi, M. Cipriani, and A. Bartolomei, "Design and preliminary performance evaluation of a four wheeled vehicle with degraded adhesion conditions," International Journal of Electric and Hybrid Vehicles, vol. 9, no. 1, pp. 1-32, 2017.

[10] S. Mohd, S. A. Zulkifli, R. G. A. Rangkuti, M. Ovinis, and N. Saad, "Electric vehicle energy management system using National Instruments' CompactRIO and LabVIEW," in Proceedings of the 2013 IEEE International Conference on Smart Instrumentation, Measurement and Applications, ICSIMA 2013, Malaysia, November 2013.

[11] R. Hibbeler, Engineering Mechanics Dynamics, Pearson Prentice Hall, Upper Saddle River, NJ, USA, 2016.

[12] D. Wu, "Twelve considerations in choosing between Gaussian and trapezoidal membership functions in interval type-2 fuzzy logic controllers," in Proceedings of the 2012 IEEE International Conference on Fuzzy Systems, FUZZ 2012, Australia, June 2012. 


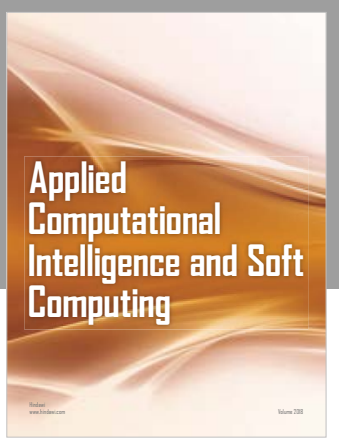

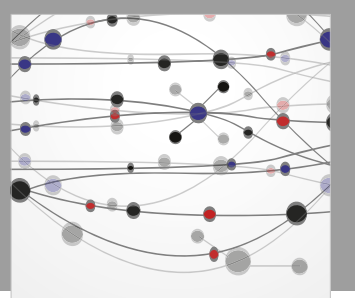

The Scientific World Journal
Submit your manuscripts at

Computing
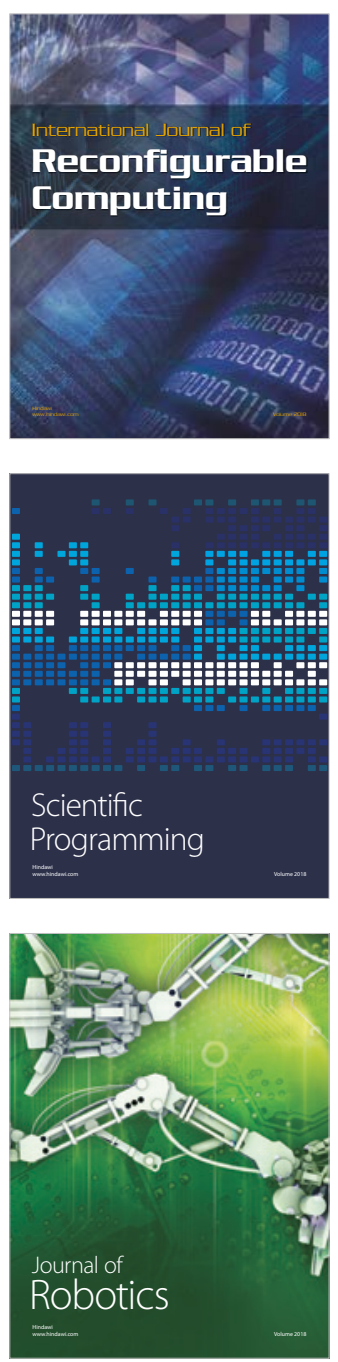

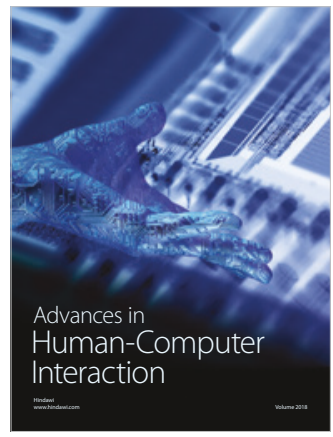

Human-Compute

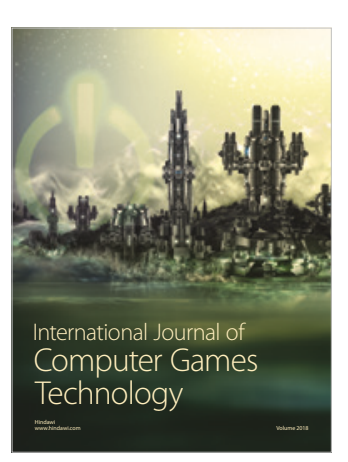

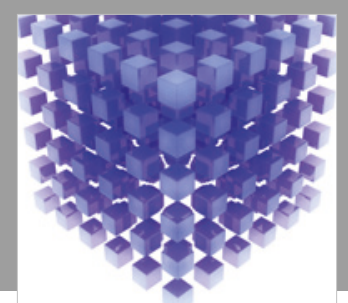

Mathematical Problems in Engineering

\section{Engincering}
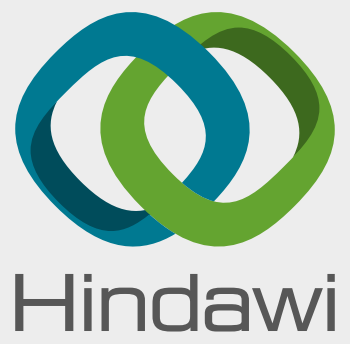

www.hindawi.com
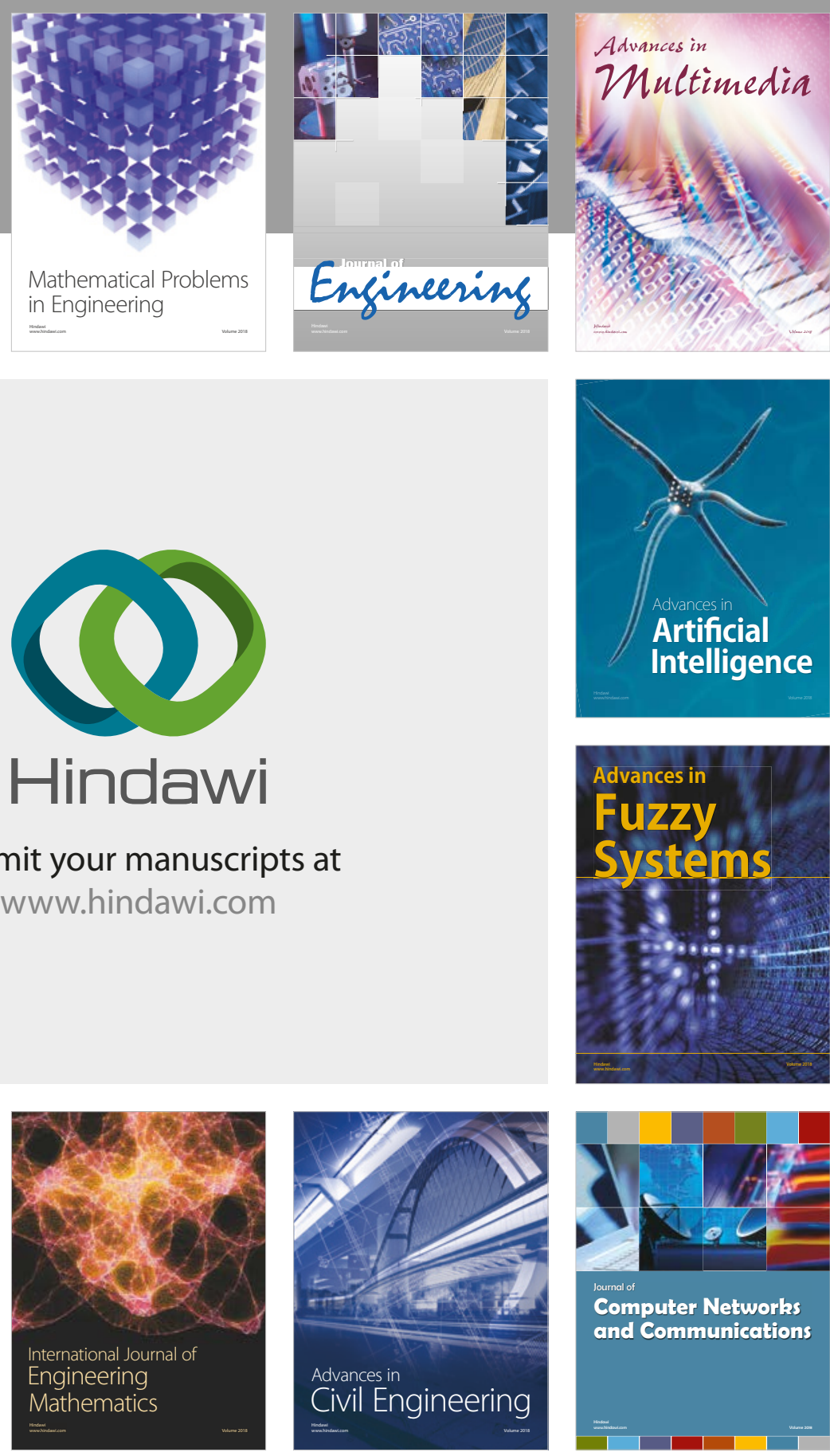

Computer Networks and Communications

Multimedia
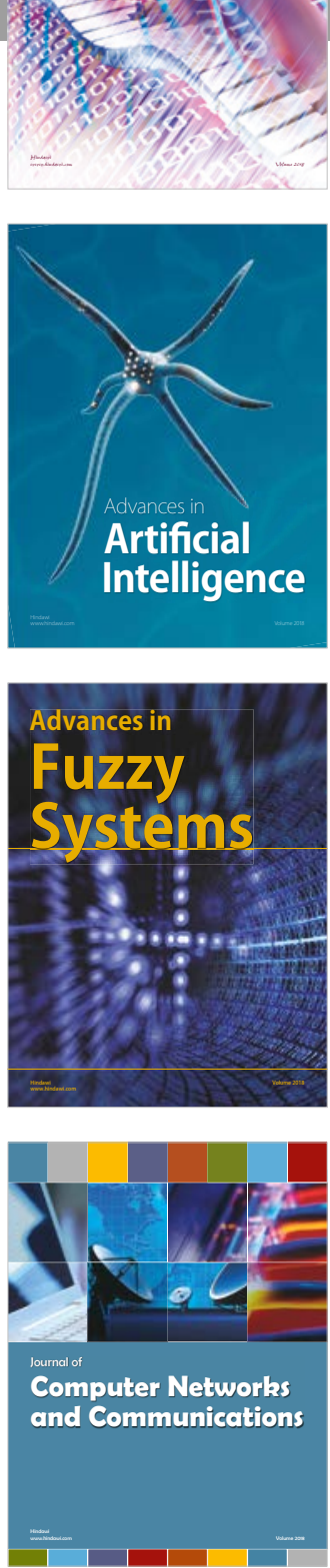

Advances in

Modelling \&

Simulation

in Engineering

interaction

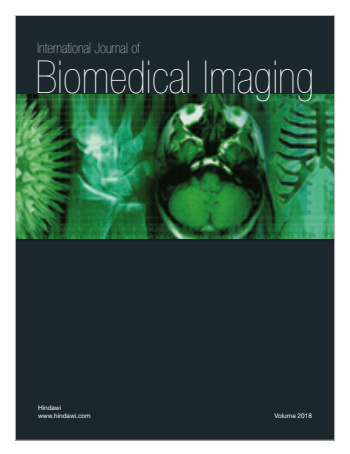

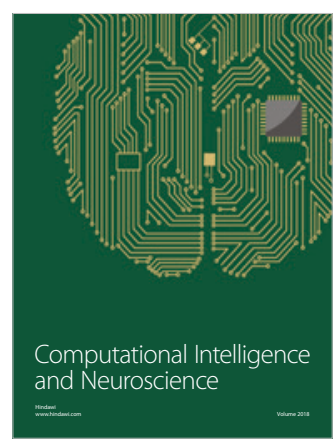

